\title{
SPLENOMESENTERIC TRUNK- COMPUTED TOMOGRAPHIC STUDY
}

\section{C.S. Ramesh Babu ${ }^{1}$, Bindu Agrawal ${ }^{* 2}$, Arjun Kumar ${ }^{3}$, O.P.Gupta ${ }^{4}$.}

1. Associate Professor of Anatomy, Muzaffarnagar Medical College. Muzaffarnagar, (UP), India.

${ }^{* 2}$ Associate Professor of Radiodiagnosis, Rama Medical College, Ghaziabad, (U.P), India.

${ }^{3}$ Second Year M.Sc.(Medical Anatomy), Rama Medical College, Ghaziabad, (U.P), India.

${ }^{4}$ Senior Radiologist, Dr.O.P.Gupta Imaging Center, Bachcha Park, Meerut. (U.P), India.

\section{ABSTRACT}

Background: Splenic artery is a relatively constant branch of celiac trunk and its variations are rare. One of the rarest variations is the occurrence of splenomesenteric trunk, common origin of splenic and superior mesenteric arteries, with an occurrence rate of less than $1.0 \%$.

Materials and Methods: We present here incidental observation of splenomesenteric trunk in three patients while retrospectively analysing contrast enhanced computed tomographic scans of 960 patients (491 males and 469 females).

Observations: The splenomesenteric trunk was observed in one female and two male patients with an incidence of $0.31 \%$. Common hepatic and left gastric arteries were arising as a common hepatogastric trunk. In one male patient the splenic artery originating from the splenomesenteric trunk was giving origin to inferior pancreaticoduodenl artery.

Discussion and Conclusion: Presence of splenomesenteric and hepatogastric trunks represents a variant anatomy of both celiac trunk and superior mesenteric arteries classified as Type IV"' of Morita's classification. Combined review of 36 studies involving a total of 9829 cases revealed the occurrence of splenomesenteric trunk in $0.09 \%$ cases (9/9829 cases). Splenic artery from splenomesenteric trunk has a variable relationship with pancreas and the splenic vein which is surgically important. Visceral artery aneurysms more commonly affect the splenic artery and the aberrant splenic artery may also develop aneurysms close to its origin.

KEY WORDS: Splenomesenteric trunk, Lienomesenteric trunk, Anomalous origin of splenic artery, Hepatogastric trunk, Superior mesenteric artery, Celiac trunk.

Address for Correspondence: Dr. Bindu Agrawal, Associate Professor of Radiodiagnosis, Rama Medical College, Ghaziabad, (U.P), India.+91-8791607725. E-Mail: mameerut@yahoo.com

\section{Access this Article online}

\section{Quick Response code}

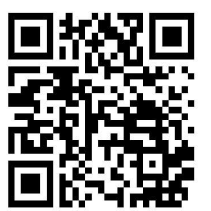

DOI: $10.16965 /$ ijar.2017.290

Web site: International Journal of Anatomy and Research ISSN 2321-4287

www.ijmhr.org/ijar.htm

Received: 11 June 2017

Peer Review: 13 June 2017

Revised: None
Accepted: 18 Jul 2017

Published (O): 31 Aug 2017

Published (P): 31 Aug 2017

\section{INTRODUCTION}

Three ventral branches of abdominal aorta (AA), the celiac artery (CA), the superior mesenteric artery (SMA) and the inferior mesenteric artery (IMA) respectively supply the derivatives of embryonic foregut, midgut and hindgut. The celiac trunk normally divides into three branches, the left gastric artery (LGA), the common hepatic artery $(\mathrm{CHA})$ and the splenic artery (SA) and this normal trifurcation pattern is observed in about $51 \%-98.3 \%$ of cases $[1,2]$ Recent analysis of combined data from 36 stud- 
ies with a total of 12196 cases has indicated that normal branching pattern of CA was present only in $89.42 \%$ of cases [3]. The SA is a large and relatively constant branch of the CA and its variations are rare. Pandey et al (2004) in their cadaveric study have observed that SA arises from CA in $90.6 \%$ cases, directly from aorta in $8.1 \%$ cases and from other sources in $1.3 \%$ cases [4]. One of the very rare variations is the occurrence of the splenomesenteric trunk (SMT) which is the common stem of origin of SA and SMA from abdominal aorta. In such cases the CA has only two branches, the LGA and the CHA and this common trunk is generally referred to as the hepatogastric trunk (HGT). Thus two common trunks, the HGT and SMT, supply foregut and midgut derivatives. Adachi (1928) did not report the occurrence of such common trunks of HGT and SMT and so did not include this branching pattern in his classification [5]. The splenomesenteric trunk was classified as Type IV"' by Morita [6] and Type IV by Michel [7].

The SMT is also referred to as lienomesenteric trunk or splenic artery arising from SMA or replaced splenic artery. The presence of HGT and SMT represents developmental anomaly of both CA and SMA and occurs in less than $1.0 \%$ cases. Since the presence of SMT and HGT as such do not cause any symptoms, the anomaly may remain undetected. Thus aberrant origin of SA from SMA is sporadically reported as incidental observations mainly as case reports in the earlier literature. The splenic artery arising from SMA has a variable, but surgically important relationship with pancreas and splenic vein. Splenic artery is the most common site for occurrence of visceral artery aneurysm and rupture of such an aneurysm leads to catastrophic consequences. We present here incidental observation of SMT while retrospectively analysing contrast enhanced computed tomographic (CECT) scans of abdomen.

\section{MATERIALS AND METHODS}

The present retrospective study was done at a single imaging centre in Meerut. The study group selected includes 960 patients (491 males and 469 females; age range $8-90$ years) who underwent contrast enhanced MDCT angiography for evaluation of hepatobiliary, pancreatic and renal pathologies, malignancies, abdominal pain and other suspected abdominal pathologies. All the scans of the subjects who had undergone previous abdominal surgery or were suffering from any intra-abdominal pathology which was likely to distort the anatomy of the region concerned and poorly enhanced scans were excluded from the study. The imaging centre routinely obtains written informed consent from the patients before contrast enhanced scanning.

All 960 patients underwent MDCT angiographic evaluation (GE optima 660, 64 channels) and received $90-100 \mathrm{~mL}$ of nonionic contrast (omnipaque) at the rate of $5 \mathrm{~mL} / \mathrm{s}$ intravenously. Scans were obtained from diaphragm to pubic symphysis and $0.625 \mathrm{~mm}$ thick sections were obtained. The scans were analyzed in a workstation (AW volume share 4.5). Volume rendered (VR) and maximum intensity projections (MIP) of axial, sagittal and coronal scans were studied for identifying the variations of celiac and superior mesenteric arteries.

\section{OBSERVATIONS}

Fig. 1: Contrast enhanced scan of a 13 year old female patient. A- Axial section, B- coronal section showing splenic artery (SA) (arrow) arising from splenomes enteric trunk (SMT) posterior to pancreas. C- Sagittal section showing splenomesenteric trunk (SMT) and hepatogastric trunk arising from abdominal aorta. Common inferior phrenic artery (CIPA) arises from hepatogastric trunk. Left gastric artery (LGA) branches off from hepatogatric trunk and is giving rise to an accessory left hepatic artery (ALHA) to left lobe of liver.

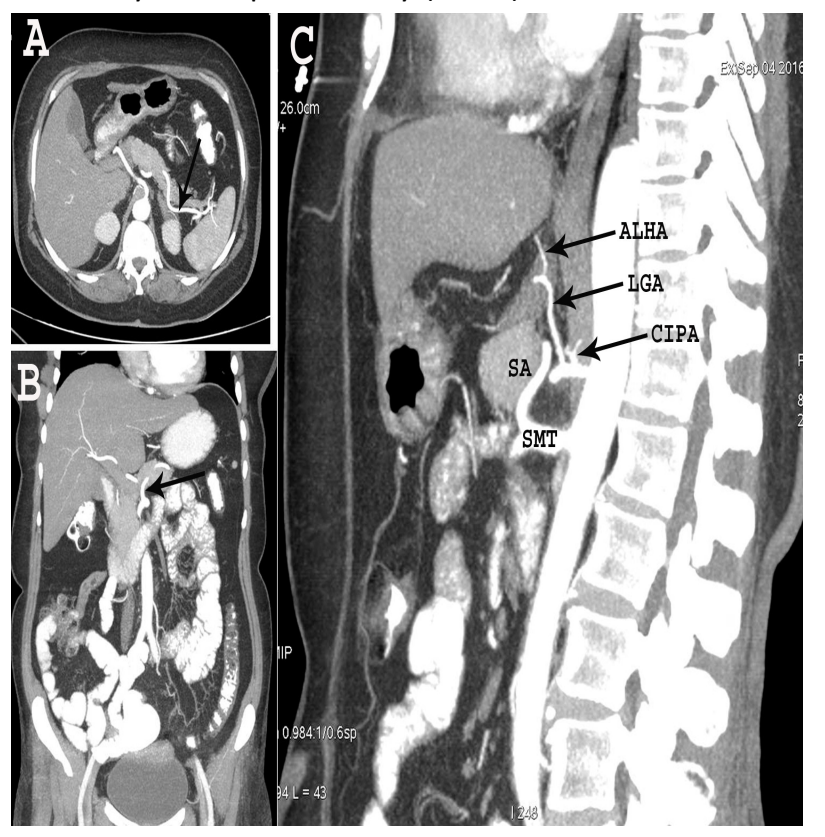


Fig. 2: Volume rendered image of abdominal aorta in a 13 year old female patient showing origin of Hepatogastric (HGT) and splenomesenteric trunks (SMT) from abdominal aorta. Common inferior phrenic artery (CIPA) is seen arising from the HGT. SA- splenic artery; CHACommon hepatic artery; SMA- superior mesenteric artery.

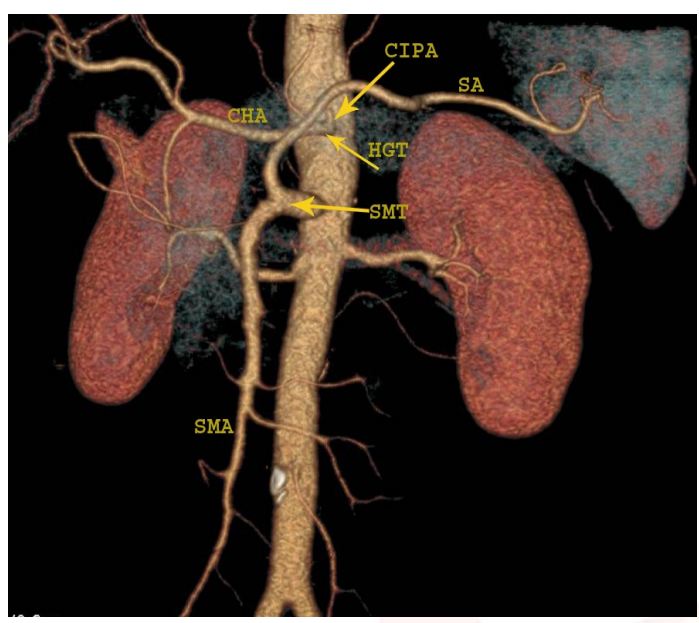

Fig. 3: Volume rendered image of abdominal aorta in a 64 year old male patient showing origin of hepatogastric (HGT) and splenomesenteric trunks (SMT) from abdominal aorta. The splenic artery (SA) is giving origin to inferior pancreaticoduodenal artery (IPDA). SMAsuperior mesenteric artery.

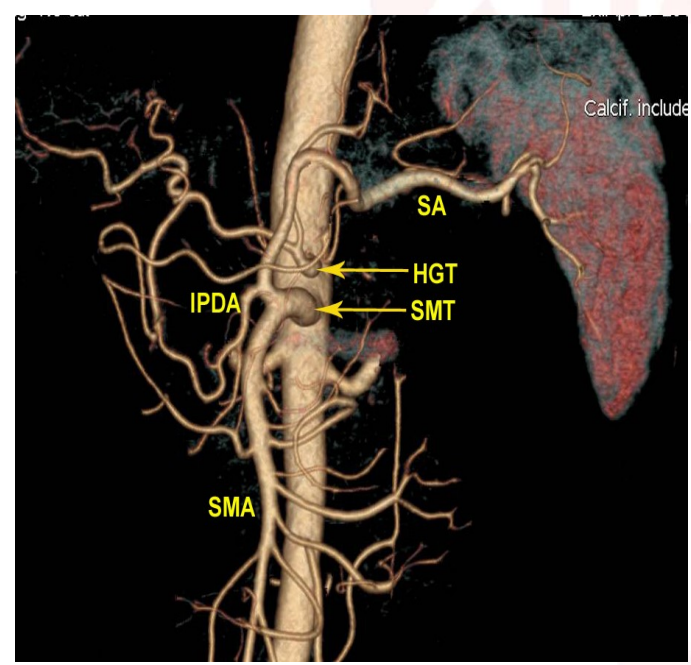

Fig. 4: Contrast enhanced scans of a 64 year old male patient. A- sagittal section, B- Coronal section showing the origin of Inferior pancreaticoduodenal artery (IDPA) from splenic artery (SA). SMT- Splenomesenteric trunk.

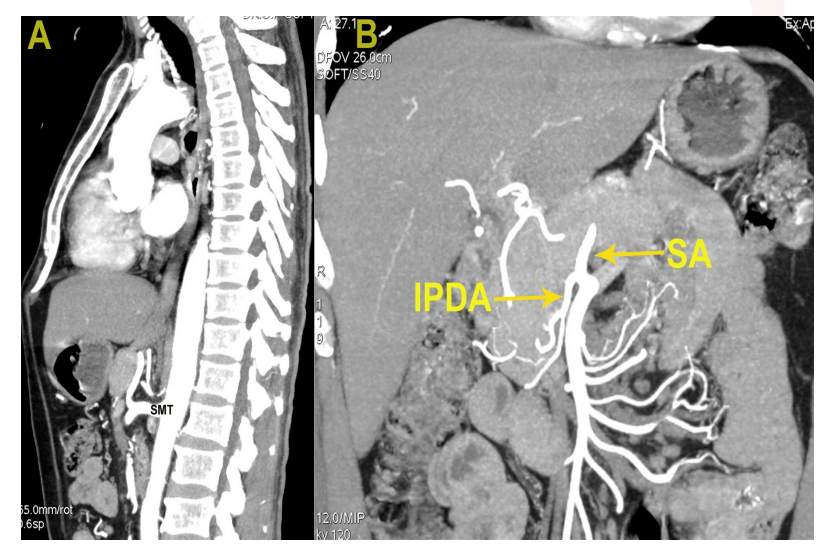

Fig. 5: Contrast enhanced scans of a 39 year old male patient. A \& B- Volume rendered images and C- Sagittal section showing origin of hepatogastric (HGT) and splenomesenteric trunks (SMT) from abdominal aorta. Splenic (SA) and Superior mesenteric arteries (SMA) arise from SMT. The hepatogastric trunk (HGT) divides into left gastric (LGA) and common hepatic arteries (CHA).

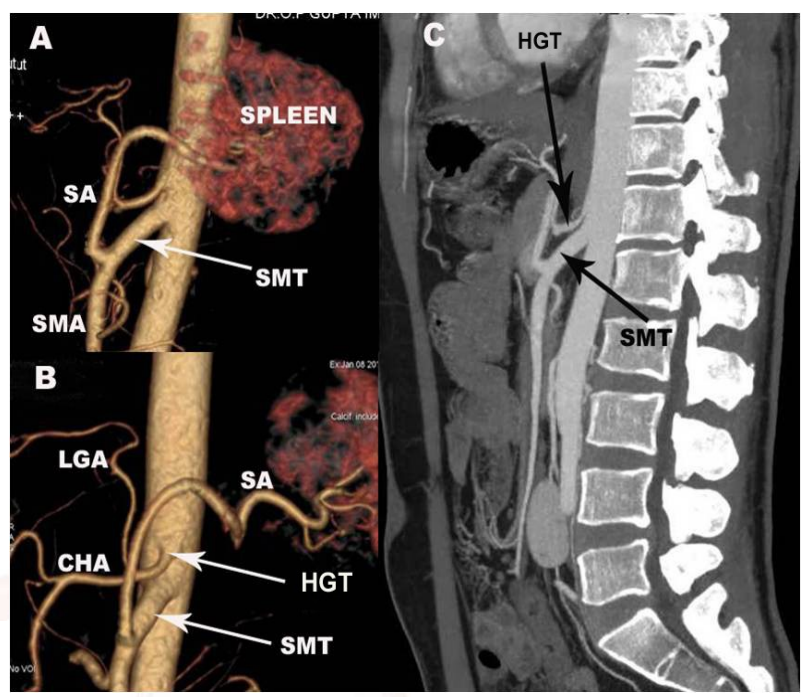

Fig. 6: A and B- Schematic diagram showing normal development of celiac (CA) and superior mesenteric arteries (SMA) from dorsal aorta. The CA and its branches and SMA develop from $10^{\text {th }}$ to $13^{\text {th }}$ ventral splanchnic arteries. These ventral splanchnic arteries are interconnected by a ventral longitudinal anastomosis. The roots of origin of $11^{\text {th }}$ and $12^{\text {th }}$ vitelline arteries from the dorsal aorta regress but these arteries remain connected to ventral longitudinal anastomosis. The part of ventral longitudinal anastomosis between the $12^{\text {th }}$ and $13^{\text {th }}$ vitelline arteries then disappears. The CA and its three branches, the LGA, SA and CHA develop from root of origin of $10^{\text {th }}$ vitelline artery, the ventral longitudinal anastomosis and $10^{\text {th }}, 11^{\text {th }}$ and $12^{\text {th }}$ vitelline arteries. The root of origin of $13^{\text {th }}$ vitelline artery persists as SMA. C- Developmental basis of splenomesenteric trunk. (SMT) Regression of origin of SA from ventral longitudinal anastomosis and development of a secondary longitudinal anastomosis between SA and the $13^{\text {th }}$ vitelline artery (SMA) gave rise to aberrant origin of SA from SMA.

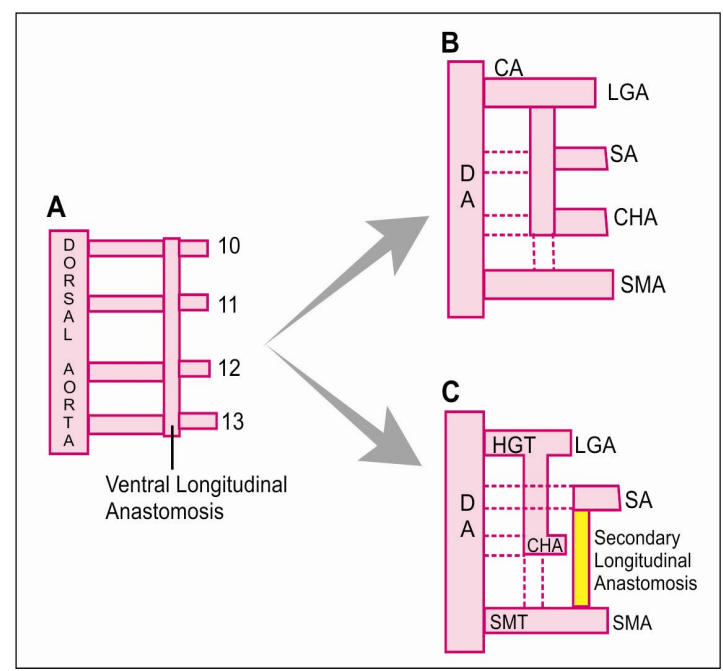


Fig. 7: Two possible variants of celiac artery (CA) in the presence of splenomesenteric trunk (SMT). A- In the presence of SMT, the two branches of celiac arterycommon hepatic (CHA) and left gastric arteries (LGA) arise independently from aorta classified by Morita as Type III"'. B- In the presence of SMT, the celiac artery is represented by hepatogastric trunk (HGT) diving into LGA and CHA, classified as Type IV'"' by Morita.

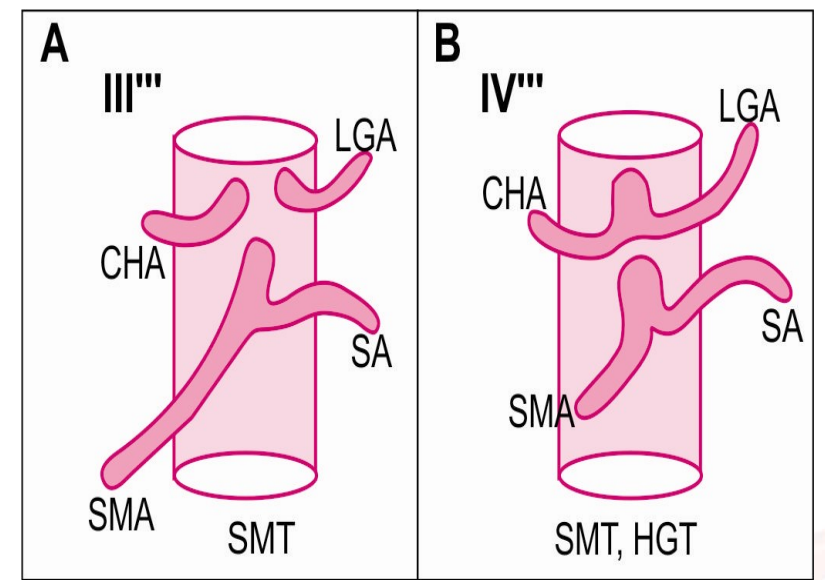

The splenomesenteric trunk (SMT) was observed in 3 cases, 2 males and 1 female with an incidence of $0.31 \%$. In a female aged 13 year, the SA arose from SMT close to its origin posterior to pancreas (Figure 1-A,1-B). The HGT divided into left gastric and common hepatic arteries and was also giving origin to common inferior phrenic artery which further divides into right and left inferior phrenic arteries. (Figure 1-C, Figure -2). The LGA was giving origin to an accessory left hepatic artery (Figure $1-C)$. In one male patient aged 64 years, the splenic artery from SMT gave rise to inferior pancreaticoduodenal artery immediately after its origin (Figure 3, Figure 4-B). In both male patients the HGT was seen dividing into $\mathrm{CHA}$ and LGA (Figure $5 \mathrm{~A}, 5 \mathrm{~B}$, 5C).

\section{DISCUSSION}

The embryonic gut is supplied by a series of ventral splanchnic (Vitelline) arteries originating from the primitive dorsal aorta. The CA and its branches and SMA develop from $10^{\text {th }}$ to $13^{\text {th }}$ ventral splanchnic arteries. These ventral splanchnic arteries are interconnected by a ventral longitudinal anastomosis. According to the scheme proposed by Tandler, the roots of origin of $11^{\text {th }}$ and $12^{\text {th }}$ vitelline arteries from the dorsal aorta regress but these arteries remain connected to ventral longitudinal anastomosis. The part of ventral longitudinal anastomosis between the $12^{\text {th }}$ and $13^{\text {th }}$ vitelline arteries then disappears. The CA and its three branches, the LGA, SA and CHA develop from root of origin of $10^{\text {th }}$ vitelline artery, the ventral longitudinal anastomosis and $10^{\text {th }}, 11^{\text {th }}$ and $12^{\text {th }}$ vitelline arteries. The root of origin of $13^{\text {th }}$ vitelline artery persists as SMA (Figure 6). It is suggested that regression of origin of SA from ventral longitudinal anastomosis and development of a secondary longitudinal anastomosis between SA and the $13^{\text {th }}$ vitelline artery (SMA) gave rise to aberrant origin of SA from SMA (Figure 6). [6]

Many types of variant branching patterns of $C A$ and SMA are expected to occur because of the complexity of their development. In the presence of SMT there are two possible variants of CA as classified by Mortita. [6] In Mortita's Type IV'" the CA is represented by HGT (common stem of origin of CHA and LGA) whereas, in Morita's Type III"' the CA is absent and CHA and LGA have independent origin from the abdominal aorta (Figure 7). All the three cases reported here belong to Morita Type IV'" with the presence of HGT and SMT.

The occurrence of splenomesenteric trunk was generally reported as case reports in the earlier literature and studies involving larger number of subjects reporting this anomaly were few. (Table-1) Ugurel et al (2010) reported the presence of SMT with HGT in 1\% cases studied (1 out of 100) [13] while Song et al observed SMT with HGT in $0.16 \%$ cases (8 out of 5002) and SMT with independent origin of $\mathrm{CHA}$ and LGA from aorta in $0.02 \%$ cases (1 out of 5002) [15]. In a retrospective analysis of MDCT scans of 1500 patients Wang et al (2014) noted the presence of SMT in $1.2 \%$ cases [20]. Analysing the celiac trunk variations in MDCT scans of 1569 patients, Torres et al (2015) reported the presence of SMT with HGT in $0.1 \%$ cases ( 2 out of 1569) [22]. Recently, in a MDCT study on 607 patients splenic artery origin from superior mesenteric was observed in a male patient with a frequency of $0.2 \%$ [23]. In an earlier study on celiacomesenteric trunk variants, we retrospectively analysed MDCT scans of 682 patients but could not find SMT [24] but when data from more number of patients were included making the total number of subjects to 960 , we detected three cases exhibiting SMT with HGT. 
Table 1: Cases of splenomesenteric trunk in the literature.

\begin{tabular}{|c|c|c|c|c|c|}
\hline SL.NO. & AUTHOR \& YEAR & MODALITY OF STUDY & SEX / AGE & NUMBER OF CASES & REMARKS \\
\hline 1 & Kou et al 1980 [8] & Cadaveric & Female - 70 & $1[0.2 \% ; 1$ out of 480$]$ & SMT \& HGT \\
\hline 2 & Suenaga et al. 1982 [9] & Cadaveric & $\begin{array}{c}\text { Female }-89 y \\
\text { Male }-80 y\end{array}$ & 2 & SMT \& HGT \\
\hline 3 & Takeuchi 1987 [10] & Cadaveric & Male - 73 & 1 & SMT \& HGT \\
\hline 4 & Harada et al 1997 [11] & Cadaveric & Male - 67 & $\begin{array}{l}1 \text { [2 out of } 1689 \\
\text { cadavers. } 0.12 \% \text { ] }\end{array}$ & $\begin{array}{c}\text { SMT \& HGT. } \\
\text { Splenic A. gave } \\
\text { origin to IPDA }\end{array}$ \\
\hline 5 & Oran et al. 2001 [12] & Angiography & Male $-55 y$ & 1 & SMT \& HGT \\
\hline 6 & Ugurel et al. 2010 [13] & MDCT Angi ography & & $1 / 100[1.0 \%]$ & SMT \& HGT \\
\hline 7 & Suma et al. 2010 [14] & Cadaveric & Female - 65 & 1 & SMT \& HGT \\
\hline 8 & Song et al. 2010 [15] & Angiography & & $8 / 5002$ cases $(0.16 \%)$ & \\
\hline 9 & Mariani et al. 2013 [16] & Cadaveric & Male - 98 y & 1 & SMT \& HGT \\
\hline 10 & Dahiphlae Varsha et al. 2013 [17] & Cadaveric & Male - $60 \mathrm{Y}$ & 1 & SMT \& HGT \\
\hline 11 & Elamin et al. 2014 [18] & CT Angiography & Male - $47 \mathrm{Y}$ & 1 & \\
\hline 12 & Osabutey, 2014 [19] & Cadaveric & Male & 1 & SMT \& HGT \\
\hline 13 & Wang et al , 2014 [20] & MDCT & & $18 / 1500(1.20 \%)$ & \\
\hline 14 & Fiorello \& Corsetti 2015 [21] & CECT & Male - 72 & 1 & $\begin{array}{c}\text { Adenocarcinoma } \\
\text { of body of } \\
\text { pancreas. }\end{array}$ \\
\hline 15 & Torres et al, 2015 [22] & MDCT & & $2 / 1569(0.10 \%)$ & \\
\hline 16 & Farqhadani et al, 2016 [23] & MDCT & Male & $1 / 607(0.2 \%)$ & \\
\hline 17 & Present Study, 2017 & CECT & $\begin{array}{c}2 \text { Males- } 39,64 \\
1 \text { Female- } 13\end{array}$ & 3 / 960 cases [0.31\%] & $\begin{array}{l}\text { Splenic A. gave } \\
\text { rise to IPDA in } \\
\text { one male patient }\end{array}$ \\
\hline
\end{tabular}

In one female patient with SMT, we observed the origin of a common inferior phrenic trunk from the HGT and similar branching pattern was also reported earlier by Kou et al [8]. Harada et al reported the origin of left inferior phrenic artery from HGT in a male cadaver with SMT [11]. In one male patient the inferior pancreaticoduodenal artery was seen arising from the splenic artery just distal to its origin from SMT and similar origin was observed earlier by Takeuchi [10] and Harada et al [11].

The aberrant splenic artery originating from the SMT has a variable and surgically important relationship with the pancreas and splenic vein. Analysing the position of splenic artery in relation to pancreas, Pandey et al noted suprapancreatic course in $74.1 \%$, anteropancreatic course in $18.4 \%$, intrapancreatic course in $4.6 \%$ and retropancreatic course in $2.8 \%$ cases [4]. The splenic artery was having a retropancreatic course to reach the splenic hilum in all cases in the present study. Thorough knowledge of anatomic location of the splenic artery and its variants is imperative for the successful accomplishment of splenic, pancreatic and other upper abdominal surgeries. Preoperative knowledge of such variant splenic artery anatomy will help to avoid the risk of adverse outcomes of surgeries [18, 21].

Splenic artery is the third common site of an abdominal arterial aneurysm and the most common site of visceral artery aneurysm [25]. Aberrant splenic artery originating from SMT can also develop aneurysms close to its origin and aneurismal rupture leads to catastrophic consequences. Till date about 36 cases of aberrant splenic artery aneurysms have been reported and successfully treated in the English literature [26, 27].

\section{CONCLUSION}

Anomalous origin of splenic artery as a common trunk with superior mesenteric artery is an unusual variation occurring in less than $1 \%$ cases. Such aberrant splenic artery generally remains asymptomatic and detected incidentally at autopsy or imaging studies of upper abdomen. Visceral artery aneurysms most commonly involve splenic artery and can also affect aberrant splenic artery. Preoperative knowledge of 
this variant anatomy of the splenic artery is essential to avoid surgical complications. Multidetector row computed tomography is an ideal imaging modality to thoroughly assess the variant anatomy of the splenic artery.

\section{ABBREVIATIONS}

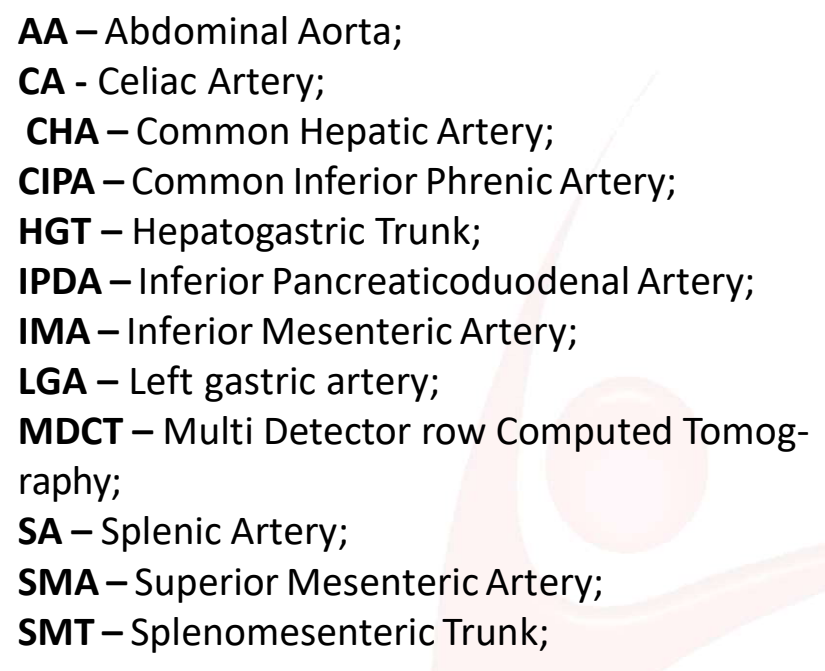

\section{ACKNOWLEDGEMENTS}

Authors sincerely acknowledge the help rendered by Mr. Sushil Kumar and Mr. Titender of Muzaffarnagar Medical College, Muzaffarnagar and Mr. Pran Prakash of Jaswant Rai Superspeciality Hospital, Meerut in preparing figures and images.

\section{Conflicts of Interests: None}

\section{REFERENCES}

[1]. Winston CB, Lee NA, Jarnagin WR, Teitcher J, DeMatt eo RP, Fong $\mathrm{Y}$, Blumgart LH. CT angiography for delineation of celiac and superior mesenteric artery variants in patients undergoing hepatobiliary and pancreatic surgery. AJR. 2007;188:w13-w19.

[2]. Hiatt JR, Gabbay J, Busuttil RW. Surgical anatomy of the hepatic arteries in 1000 cases. Ann Surg. 1994;220:50- 52.

[3]. Panagouli E, Venieratos D, Lolis E, Skandalakis P. Variations in the anatomy of the celiac trunk: a systematic review and clinical implications. Ann Anat. 2013;195:501-511

[4]. Pandey S.K., Bhattacharya S, Mishra RN, Shukla VK. Anatomical variations of the splenic artery and its clinical implications. Clin Anat. 2004; 17 (6): 497502.

[5]. Adachi B. Das Arteriensystem der Japaner. 2. Verlag der Kaiserlich-Japanischen Universitat zu Kyoto; 1999:18-71.

[6]. Morita M. Reports and conception of three anomalous cases in the area of the celiac and superior mesenteric arteries. Igaku Kenkyu. 1935;9:159-172 (in Japanese).

[7]. Michels N. Blood supply and anatomy of the upper abdominal organs. Lippincott, Philadelphia, 1955.

[8]. Kou S, Takemura A, Irifune T, Irifune T. A case of splenic artery arising from the superior mesenteric artery. Okajimas Folia Anat Jpn. 1980; 57: 241-250.

[9]. Suenaga Y, Nakamura R, Inoue K, Terashima T, Takeda $M$, Inoue $Y$. Two cases of a lieno-mesenteric trunk. Okajimas Folia Anat Jpn. 1982; 58 (4-6): 1249-1258.

[10]. Takeuchi K. An anomalous case of the splenic artery. Okajimas Folia Anat Jpn. 1987; 63 (6): 407414.

[11]. Harada H, Yamaki K-I, Doi Y, Hirata T, Saga T, Nishida T, Nishimura H, Yoshizuka M. An anomalous case of the gastro-hepatic and spleno-mesenteric trunks independently arising from the abdominal aorta. The Kurume Medical Journal. 1997; 44: 237-240.

[12]. Oran I, Yesildaq A, Menis A. Aortic origin of right hepatic artery and superior mesenteric origin of splenic artery: two rare variations demonstrated angiographically. Surg Radiol Anat. 2001; 23 (5): 349-352.

[13]. Ugurel MS, Battal B, Bozlar U, Nural MS, Tasar M, Ors F, Saglam M, Karademir I. Anatomical variations of the hepatic arterial system, celiac trunk and renal arteries: an analysis with multidetector CT angiography. Br J Radiol. 2010; 83: 661-667.

[14].Suma HY, Ramachandra Rao K, Jayanthi V. Splenomesenteric trunk. A case report. Anatomica Karnataka. 2010; 4 (3): 12-14.

[15]. Song SY, Chung JW, Yin YH, Jae HJ, Kim HC et al . Celiac axis and common hepatic artery variations in $\mathbf{5 0 0 2}$ patients. Systematic analysis with spiral CT and DSA. Radiology, 2010; 255 (1): 278-288.

[16]. Mariani GA, Maroni L, Bianchi L, Broccoli A, Lazzarini E, Marchegiani G, et al. Hepato-gastric ans splenomesenteric arterial trunks: anatomical variation report and review of the literature. Italian J Anat Embryol. 2013; 118(2): 217-222.

[17]. Dahiphale Varsha P, Selukar Mangesh S, Kulkarni Promod R. Variations in branching pattern of superior mesenteric artery. International Journal of Recent Trends in Science and Technology. 2013; 5 (3): 166-167.

[18]. Elamin D, El-Salhat H, Bekdache O. Aberrant splenic artery: case report of splenic artery originating from superior mesenteric artery. J Gastroenterol. Hepatol. Res. 2014; 3 (3): 1017-1018.

[19]. Osabutey CK. Anatomic variation of celiac and testicular arteries. Anat J Afr. 2014; 3 (3): 368-371.

[20]. Wang Y, Cheng C, Wang L, Li R, Chen J, Gong S. Anatomical variations in the origins of the celiac axis and the superior mesenteric artery: MDCT angiographic findings and their probable embryological mechanisms. Eur Radiol. 2014; 24 (8): 17771784.

[21]. Fiorello B, Corsetti R. Splenic artery originating from the superior mesenteric artery: An unusual but important anatomic variant. The Ochsner Journal. 2015: 15: 476-478 
[22]. Torres K, Staskiewicz G, Demisow M, Pietrzyk L, Torres A, Szukata M, Czekajska-Chehab E, Drop A. Anatomical variations of the celiac trunk in the homogenous Polish population. Folia Morphol. 2015;74 (1): 9399.

[23]. Farqhadani M, Momeni M, Hekmatnia A, Momeni F, Mahdavi MMB. Anatomical variation of celiac axis, superior mesenteric artery and hepatic artery: Evaluation with multidetector computed topography angiography. J Res Med Sci. 2016; 21: 129.

[24]. Ramesh Babu CS, Joshi S, Gupta KK, Gupta OP. Celiacomesenteric trunk and its variants a multidetector row computed tomographic study. J Anat Soc India. 2015; 64: 32-41.
[25]. Tochii M, Ogino H, Sasaki H, Matsuda H, Minatoya K, Yagihara K, Kitamura S. Successful surgical treatment of aneurysm for splenic artery with anomalous origin. Ann Thorac Cardiovasc Surg. 2005; 11: 346-349.

[26]. Zhou W, Qiu J, Yuan Q, Zhou W, Xiong J, Zeng Q. Successful treatment of aberrant splenic artery aneurysm with a combination of coils embolization and covered stents. BMC Surgery. 2014; 14: 62.

[27]. Bhoil R, Tomar A, Makhaik S, Sood RG, Nayyar N. Aneurysm of an aberrant splenic artery: An extremely rare occurrence. Vascular Online First, published on July 28, 2015 as doi:10.1177/ 1708538115597372.

How to cite this article:

C.S. Ramesh Babu, Bindu Agrawal, Arjun Kumar, O.P.Gupta SPLENOMESENTERIC TRUNK- COMPUTED TOMOGRAPHIC STUDY. Int J Anat Res 2017;5(3.2):4216-4222. DOI: 10.16965/ ijar.2017.290 